\title{
Subcellular localization of DJ-1 in human HL-60 leukemia cells in response to diallyl disulfide treatment
}

\author{
QINGYE LI $^{1 *}$, YUXIAN TANG $^{2 *}$, JING QIN $^{1}$, LAN YI $^{1}$, YENING YANG $^{1}$, \\ JUAN WANG $^{1}$, JIE HE ${ }^{1}$, QI SU ${ }^{1}$ and HUI TAN ${ }^{1}$ \\ ${ }^{1}$ Cancer Research Institute, University of South China, Hengyang, Hunan 421001; ${ }^{2}$ Department of Pathology, \\ The Central Hospital of Yongzhou, Yongzhou, Hunan 425000, P.R. China
}

Received October 9, 2015; Accepted September 2, 2016

DOI: $10.3892 / \mathrm{mmr} .2016 .5831$

\begin{abstract}
Diallyl disulfide (DADS) has been demonstrated to exert potent anticancer effects in vitro and in vivo. Previous studies indicate that DADS may induce the differentiation and/or apoptosis of human leukemia cells in vitro. However, the mechanisms underlying these anticancer effects remain elusive. The aim of the present study was to investigate alterations in the subcellular localization of protein deglycase DJ-1 (also known as Parkinsonism associated deglycase-7, PARK-7) in the cytoplasm, nucleus and mitochondria of human leukemia HL-60 cells induced by DADS, in order to provide novel experimental evidence for the molecular mechanisms underlying the anticancer mechanisms of DADS in leukemia cells. HL-60 cells induced by DADS were collected at different time points, and proteins from the cytoplasm, nucleus and mitochondria of the cells were isolated using specific cellular component isolation kits. The protein expression levels of DJ-1 in these subcellular fractions of HL60 cells following exposure to DADS for varying lengths of time, were determined using western blotting, immunocytochemistry and immunofluorescence techniques. Following exposure of HL-60 cells to $1.25 \mathrm{mg} / \mathrm{l}$ DADS for $8 \mathrm{~h}$, the protein expression levels of DJ-1 were significantly decreased in the cytoplasm, while nuclear fractions exhibited a significant increase in DJ-1 expression when compared with untreated controls. The protein expression levels of DJ-1 in mitochondria of HL-60 cells were significantly decreased following treatment with 5 and $10 \mathrm{mg} / \mathrm{l}$ DADS. These results demonstrate that exposure of HL-60 cells to low concentrations of DADS may promote DJ-1 protein translocation from the cytoplasm to the nucleus,
\end{abstract}

Correspondence to: Professor Hui Tan, Cancer Research Institute, University of South China, 28 Changsheng Road, Hengyang, Hunan 421001, P.R. China

E-mail: tanhuiketizu@163.com

\section{*Contributed equally}

Key words: protein deglycase DJ-1, diallyl disulfide, leukemia, subcellular localization which suggests that DJ-1 may function as a transcription factor or cofactor binding protein in the process of cell differentiation. The expression of DJ-1 in mitochondria may be associated with induction of apoptosis in HL-60 cells treated with moderate doses of DADS.

\section{Introduction}

Acute myeloid leukemia (AML) is the most common type of acute leukemia diagnosed in adults. Although most patients achieve complete remission following induction chemotherapy treatment, the majority of patients relapse after achieving clinical remission $(1,2)$. Differentiation therapy is an alternative AML treatment method based on the induction of leukemic blast cells to mature beyond the differentiation block, which may restore a normal cellular phenotype and lead to cell cycle arrest (3). The present study was performed in the HL-60 cell line, which was originally isolated from an acute promyelocytic leukemia patient, and is a well-characterized model for studying terminal differentiation events (4).

Diallyl disulfide (DADS) is a major sulfur compound present in garlic, which exerts anti-inflammatory and immune-modulatory effects and enhances sympathetic nervous system activity (5). Previous studies have demonstrated that DADS exerts multiple antitumor effects in a number of different tumor types by activating metabolic enzymes that detoxify carcinogens, suppressing DNA synthesis, inhibiting cell proliferation, angiogenesis or invasion, and preventing the induction of cell cycle arrest, apoptosis and differentiation (6-8).

In a previous study, DADS increased the reduction ability of nitroblue tetrazolium in a time-dependent manner in human leukemia HL-60 cells (9). In addition, DADS inhibited the growth and induced the differentiation of these cells (9). Furthermore, it was reported that DADS induced apoptosis in HL-60 cells (10). DADS-induced apoptosis involved cell cycle arrest in G2/M phase, increased histone acetylation and endoplasmic reticulum (ER) stress, and activation of the Fas-mediated cell death pathway (11). Using proteomic-screening technology, a previous study demonstrated a significant reduction in the protein expression levels of protein deglycase DJ-1 (also known as Parkinsonism associated deglycase-7, PARK-7) in HL-60 cells following DADS treatment (12). 
DJ-1, originally identified as an oncogene, appears to be involved in a number of diverse biological processes (13), including regulation of transcription (14), oxidative stress mechanisms $(15,16)$, mitochondrial regulation, fertilization and TNF-related apoptosis-inducing ligand-mediated apoptosis in tumor cells (17). At the subcellular level, DJ-1 is primarily localized to the cytosol, but is expressed at low levels in the mitochondria and nucleus (18). Under oxidative stress conditions, DJ-1 preferentially translocates to the mitochondrial matrix and the intermembrane space in order to initiate protective mechanisms (19). Despite the known association between DJ-1 and cancer $(20,21)$, the precise association between the biochemical function of DJ-1 and its subcellular localization remains unclear.

Previous studies have demonstrated that DADS inhibits the proliferation of HL-60 cells by downregulating the expression of DJ-1 protein (22). In addition, siRNA-mediated suppression of DJ-1 expression enhanced the production of mature granulocyte cell lines and promoted the differentiation of HL-60 cells induced by DADS (22).

The aim of the present study was to investigate the expression of DJ-1 in the cytoplasm, nucleus and mitochondria of HL-60 cells induced by DADS, in order to determine whether the subcellular location of DJ-1 is altered following exposure to DADS for varying lengths of time. These results provide novel experimental evidence for the molecular mechanisms underlying the antitumor effects of DADS in human leukemia cells.

\section{Materials and methods}

Cell culture and treatments. HL-60 cells, obtained from The Cancer Research Institute, Xiangya Medical College, Central South University (Changsha, China), were maintained in L-glutamine-containing RPMI 1640 medium (HyClone; GE Healthcare Life Sciences, Logan, UT, USA), supplemented with $10 \%$ fetal bovine serum (Zhejiang Tianhang Biotechnology Co., Ltd., Hangzhou, China) and without antibiotics. The cells were incubated at $37^{\circ} \mathrm{C}$ in $5 \% \mathrm{CO}_{2}$ for 2 days before they were harvested. DADS (purity $80 \%$; the remaining $20 \%$ being diallyl trisulfide and diallyl sulfide) was purchased from Sigma-Aldrich; Merck Millipore (Darmstadt, Germany), dissolved in Tween 80 at $8 \mathrm{mg} / \mathrm{ml}$ and stored at $-20^{\circ} \mathrm{C}$. HL-60 cells $\left(2 \times 10^{6}\right.$ cells $\left./ \mathrm{ml}\right)$ in the logarithmic growth phase were placed in fresh medium prior to use in experiments. DADS was diluted to $1.25,2.5,5$ and $10 \mathrm{mg} / 1$ with culture medium and added to cell cultures. Following 4,8 or 12 h DADS treatment, cells were collected for analysis.

Cytoplasmic, nuclear and mitochondrial protein extraction. HL-60 cells $\left(2 \times 10^{6}\right.$ cells $\left./ \mathrm{ml}\right)$ in the logarithmic growth phase were harvested and washed with ice-cold phosphate-buffered saline (PBS). Nuclear and cytoplasmic proteins were isolated from cells using NE-PER Nuclear and Cytoplasmic Extraction Reagents (Thermo Fisher Scientific, Inc., Waltham, MA, USA) according to the manufacturer's instructions. Briefly, cells were transferred to a $1.5 \mathrm{ml}$ microcentrifuge tube and pelleted by centrifugation at $500 \times \mathrm{g}$ for $5 \mathrm{~min}, 4^{\circ} \mathrm{C}$ before a pipette was used to remove the supernatant. Ice-cold Cytoplasmic Extraction Reagent (CER) I was subsequently added to the cell pellet, and the tube was vortexed vigorously for $10 \mathrm{sec}$ before incubating on the ice for $20 \mathrm{~min}$. Ice-cold CER II, was added to the solution, and the tube was vortexed for $5 \mathrm{sec}$ and then centrifuged for $10 \mathrm{~min}, 4^{\circ} \mathrm{C}$ at maximum speed in a microcentrifuge $(160,000 \times \mathrm{g})$. The resulting supernatant was the cytoplasmic extract, and the insoluble fraction, containing the cell nuclei, was dissolved in ice-cold Nuclear Extraction Reagent. The sample was subsequently vortexed for $15 \mathrm{sec}$ and then incubated on ice for $10 \mathrm{~min}$. This step was repeated 4 times over the course of $40 \mathrm{~min}$ and was followed by centrifugation at maximum speed $(160,000 \mathrm{x} \mathrm{g})$ in a microcentrifuge for $30 \mathrm{~min}$ at $4^{\circ} \mathrm{C}$, to obtain the nuclear protein extract.

Mitochondrial proteins were isolated using a Cell Mitochondria Isolation kit (Beyotime Institute of Biotechnology, Haimen, China) according to the manufacturer's instructions. Briefly, cells $\left(2 \times 10^{6}\right.$ cells $\left./ \mathrm{ml}\right)$ in the logarithmic growth phase were harvested and washed twice with ice-cold PBS. Cells were incubated with cell lysis buffer ( $1 \mathrm{ml}$ cell lysis buffer $/ 2 \times 10^{7}$ cells) for $10 \mathrm{~min}$ at $4^{\circ} \mathrm{C}$, before they were homogenized with a glass homogenizer. The cell lysate was centrifuged at $600 \mathrm{x} g$ for $10 \mathrm{~min}$ at $4^{\circ} \mathrm{C}$ to remove any remaining whole cells, and the supernatant was further centrifuged at $11,000 \mathrm{x} g$ for $10 \mathrm{~min}$ at $4^{\circ} \mathrm{C}$. The supernatant was removed and the remaining mitochondrial pellet was resuspended in mitochondrial lysis buffer at $4^{\circ} \mathrm{C}$, and centrifuged at $24,000 \times \mathrm{g}$ for $15 \mathrm{~min}$ at $4^{\circ} \mathrm{C}$ to remove the cell nuclei. Mitochondrial extracts were stored at $-80^{\circ} \mathrm{C}$ until required. The concentration of cytoplasmic, nuclear and mitochondrial protein extracts was determined using a bicinchoninic acid assay kit (Pierce; Thermo Fisher Scientific, Inc.).

Western blot analysis. Sample protein extracts were denatured by boiling at $100^{\circ} \mathrm{C}$ for $5 \mathrm{~min}$ in $5 \mathrm{X}$ SDS-PAGE Sample Loading buffer (Beyotime Institute of Biotechnology), at a ratio of 4:1. Proteins were then separated by sodium dodecyl sulfate-polyacrylamide gel electrophoresis and transferred to polyvinylidene difluoride membranes by electroblotting. Membranes were blocked using 5\% non-fat dry milk in tris-buffered saline with $0.1 \%$ Tween 20 (TBST) buffer for $2 \mathrm{~h}$ at room temperature. Membranes were subsequently incubated with mouse monoclonal anti-DJ-1 (dilution, 1:3,000; catalog no. 05-828; EMD Millipore, Billerica, MA, USA), mouse anti- $\beta$-actin (dilution, 1:2,000; catalog no. A5441; Sigma-Aldrich; Merck Millipore), rabbit polyclonal anti-TATA-box binding protein (TBP; dilution, 1:2,000; catalog no. 22246-1-AP; ProteinTech Group, Inc., Chicago, IL, USA), or rabbit polyclonal anti-voltage-dependent anion channel 1 (VDAC1; dilution, 1:1,000; catalog no. 10866-1-AP; ProteinTech Group, Inc.) primary antibodies overnight at $4^{\circ} \mathrm{C}$. $\beta$-actin, VDAC1 and TBP were used to normalize protein loading in cytoplasmic, mitochondrial and nuclear protein extracts, respectively. Membranes were then washed with TBST and incubated for $1 \mathrm{~h}$ with horseradish peroxidase (HRP)-conjugated goat anti-mouse $\mathrm{IgG}$, (dilution, 1:2,000; catalog no. CW0102M; Beijing ComWin Biotech Co., Ltd., Beijing, China) or HRP-conjugated goat anti-rabbit IgG, (dilution, 1:1,000; catalog no. CW0103M; Beijing ComWin Biotech Co., Ltd.). After washing the membranes in TBST, antibody binding was detected using Ponceau $\mathrm{S}$ staining solution (Beyotime Institute of Biotechnology). Densitometry was performed using AlphaImager software version 3.3.0 (ProteinSimple Bioscience and Technology Co., Ltd., Shanghai, 

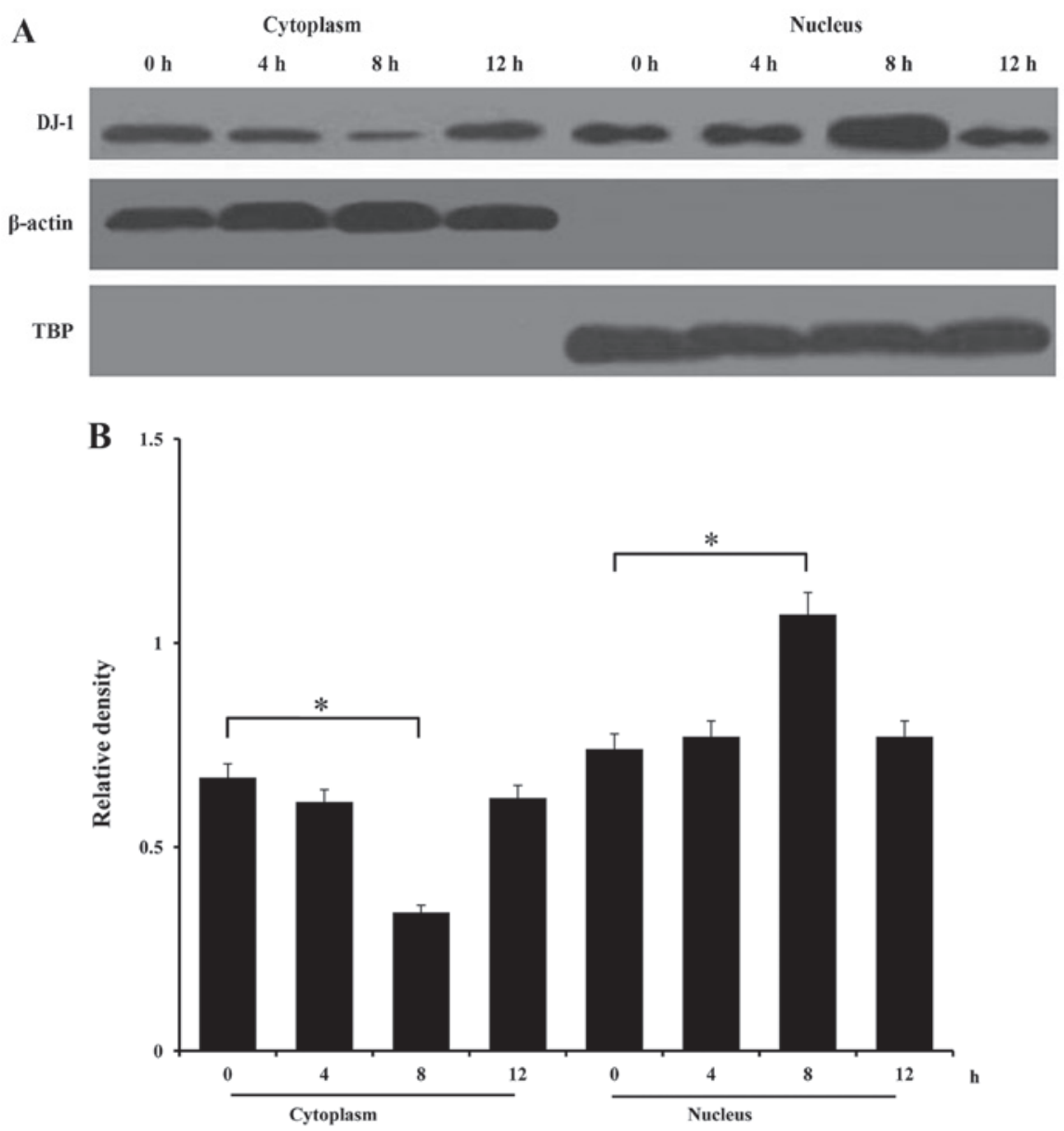

Figure 1. (A) Representative western blot and (B) quantification of band densities of DJ-1 protein expression in the cytoplasm and nucleus of HL-60 cells treated with $1.25 \mathrm{mg} / 1$ DADS for $0,4,8$ or $12 \mathrm{~h}$. $\beta$-actin was used as a loading control for DJ-1 expression in the cytoplasm. ${ }^{*} \mathrm{P}<0.05 \mathrm{vs} .0 \mathrm{~h}$ untreated controls. DADS, diallyl disulfide.

China), and target protein expression levels were normalized to the reference protein expression levels.

Immunocytochemistry and immunofluorescence. Immunocytochemical analysis of DJ-1 expression in HL-60 cell specimens was performed using a DAB Detection Kit (Fuzhou Maixin Biotech, Co., Ltd., Fuzhou, China). Cells (20 $\mu$ l/coverslip; $1 \times 10^{6}$ cells/l) were first seeded on coverslips and fixed with $95 \%$ ethanol for $30 \mathrm{~min}$ at room temperature. Endogenous peroxidase activity was inhibited by incubating cells in $0.3 \%$ (v/v) hydrogen peroxide in methanol for $10 \mathrm{~min}$, followed by washing three times with PBS for 5 min each time. Samples were then blocked with $10 \%(\mathrm{v} / \mathrm{v})$ normal goat serum diluted in PBS for $30 \mathrm{~min}$, before incubating with the anti-DJ-1 antibody [diluted, 1:200 in PBS containing 3\% (wt/vol) bovine serum albumin; catalog no. 05-828; EMD Millipore] overnight at $4^{\circ} \mathrm{C}$. After washing three times with PBS for 5 min each time, cells were incubated with a biotinylated goat anti-mouse $\mathrm{IgG}$ antibody (dilution, 1:100; catalog no. bs-0296G-Bio; BIOSS, Beijing, China) for $15 \mathrm{~min}$ at room temperature, followed by three additional 5-min wash steps with PBS. Cells were subsequently incubated with streptavidin-avidin-HRP for $20 \mathrm{~min}$ at room temperature, and then washed with PBS as described above. Samples were visualized by incubating cells in 3,3'-diaminobenzidine at room temperature for $2 \mathrm{~min}$. After counterstaining with hematoxylin for $30 \mathrm{sec}$ and rinsing with tap water, samples were immediately dehydrated by sequential immersion in gradient ethanol solutions. Images were obtained using a light microscope (Olympus Corporation, Tokyo, Japan).

Immunofluorescence analysis of DJ-1 expression in HL-60 cells was achieved by first seeding cells (20 $\mu \mathrm{l} /$ coverslip; $1 \times 10^{6}$ cells/l) on coverslips and fixing with $4 \%$ paraformaldehyde for $20 \mathrm{~min}$ at room temperature. Samples were then blocked in PBS containing 0.2\% Triton X-100 and 5\% normal goat serum for $1 \mathrm{~h}$ at room temperature. Cells were subsequently incubated with mouse monoclonal anti-DJ-1 (diluted, 1:200 in PBS containing $0.2 \%$ Triton X-100 and $1 \%$ normal goat serum; catalog no. 05-828; EMD Millipore) at $4^{\circ} \mathrm{C}$ overnight. After washing three times with PBS, cells were incubated with a Texas Red-conjugated goat anti-mouse IgG (dilution, 1:50; catalog no. SA00005-1; ProteinTech Group, Inc.) secondary antibody at room temperature for $1 \mathrm{~h}$. Nuclei were stained with 4',6-diamidino-2-phenylindole for $5 \mathrm{~min}$ at room temperature, before the cells were washed twice with PBS and analyzed using an EVOS FL Auto fluorescence microscope (Thermo Fisher Scientific, Inc.).

Statistical analysis. Experiments were repeated a minimum of three times. Data are presented as the mean \pm standard deviation. Differences between treatment groups were analyzed 

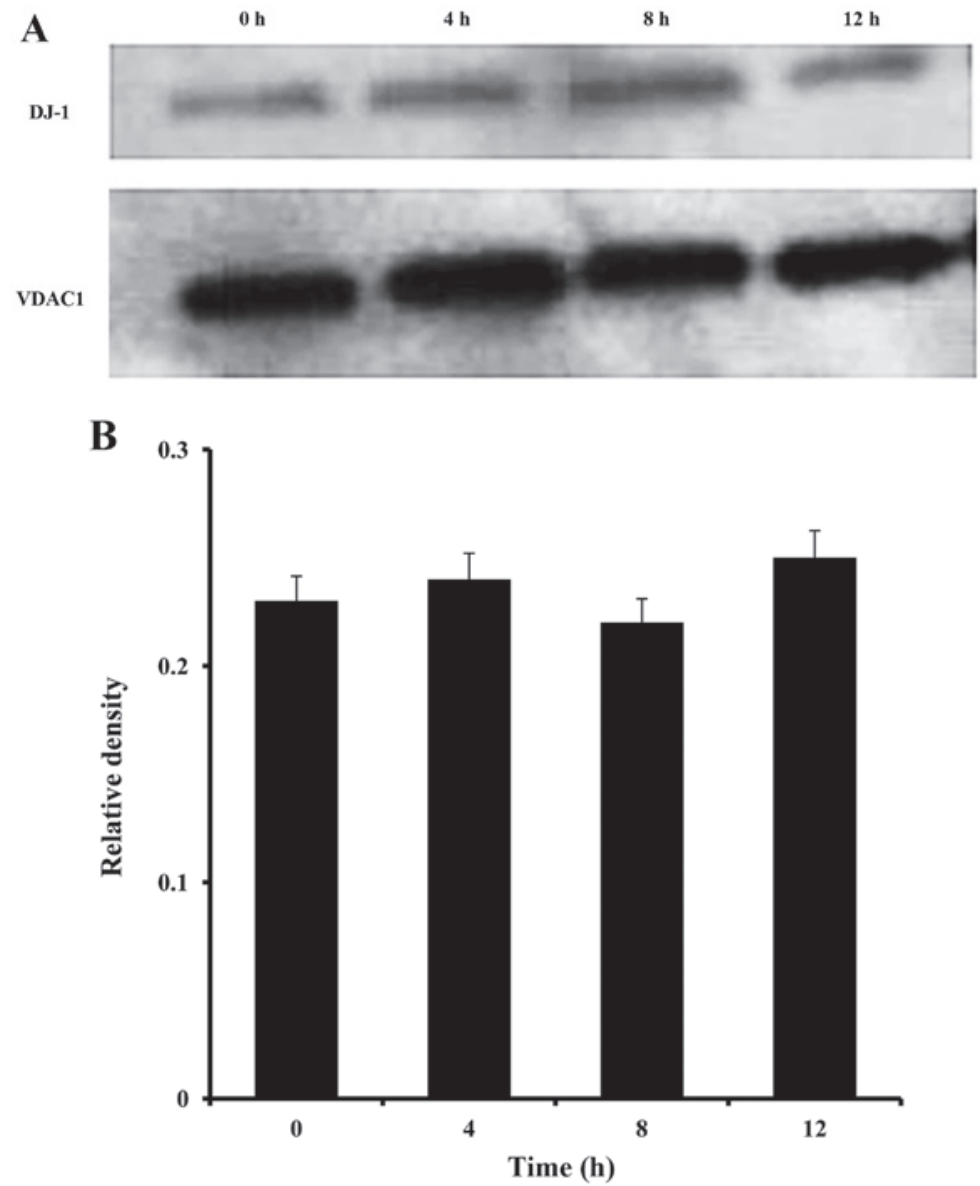

Figure 2. (A) Representative western blot and (B) quantification of band densities of DJ-1 protein expression in the mitochondria of HL-60 cells following treatment with $1.25 \mathrm{mg} / 1$ DADS for $0,4,8$ or $12 \mathrm{~h}$. DADS, diallyl disulfide.

with the Student's t-test using GraphPad Prism software version 5.01 (GraphPad Software, Inc., La Jolla, CA, USA). $\mathrm{P}<0.05$ was considered to indicate a statistically significant difference.

\section{Results}

DADS promotes DJ-1 protein translocation from the cytoplasm to the nucleus in HL-60 cells. As shown in Fig. 1, western blot analysis demonstrated that the protein expression levels of cytoplasmic DJ-1 in HL-60 cells treated with DADS $(1.25 \mathrm{mg} / \mathrm{l}$ for $8 \mathrm{~h})$ were significantly reduced $(\mathrm{P}=0.013)$, while the nuclear expression levels of DJ-1 were significantly increased $(\mathrm{P}=0.032)$.

$D A D S$ decreases the expression of DJ-1 in the mitochondria of HL-60 cells. As shown in Fig. 2, western blot analysis indicated that the protein expression levels of DJ-1 in the mitochondria of HL-60 cells following treatment with by DADS $(1.25 \mathrm{mg} / \mathrm{l})$ were not significantly different at 4,8 and $12 \mathrm{~h}$ when compared with untreated controls $(\mathrm{P}=0.178)$. By contrast, exposure of HL-60 cells to 5 and $10 \mathrm{mg} / \mathrm{l}$ DADS for $8 \mathrm{~h}$ was associated with a significant decrease in mitochondrial DJ-1 protein expression levels ( $\mathrm{P}=0.029$; Fig. 3 ).

Increased levels of DJ-1 in the nucleus of HL-60 cells following exposure to DADS as determined by immunocytochemical analysis. As presented in Fig. 4A, immunocytochemical analysis demonstrated that DJ-1 protein expression was detected primarily in the cytoplasm, and low levels were detected in the nucleus. By contrast, following exposure of HL-60 cells to $1.25 \mathrm{mg} / \mathrm{l}$ DADS for $8 \mathrm{~h}$, an increase in the expression of DJ-1 protein was observed in the nucleus (Fig. 4B).

Increased expression of DJ-1 in the nucleus of HL-60 cells following exposure to DADS as determined by immunofluorescence analysis. As demonstrated in Fig. 4, DJ-1 expression was observed primarily in the cytoplasm, with low levels observed in the nucleus. In order to confirm the observed increase in DJ-1 expression in the nucleus following exposure of cells to DADS, the intracellular distribution DJ-1 in HL-60 cells was analyzed by immunofluorescence. As shown in Fig. 5, an increase in the number of DJ-1-positive nuclei were observed in HL-60 cells following exposure to DADS $(1.25 \mathrm{mg} / \mathrm{l})$ for $8 \mathrm{~h}$ (Fig. 5F), when compared with untreated controls (Fig. 5C). These results provide additional evidence demonstrating that DJ-1 translocated from the cytoplasm to the nucleus following DADS treatment.

\section{Discussion}

Previous studies have reported that DADS exerts a number of beneficial effects by decreasing the formation of carcinogen-induced cancers and inhibiting the proliferation of 

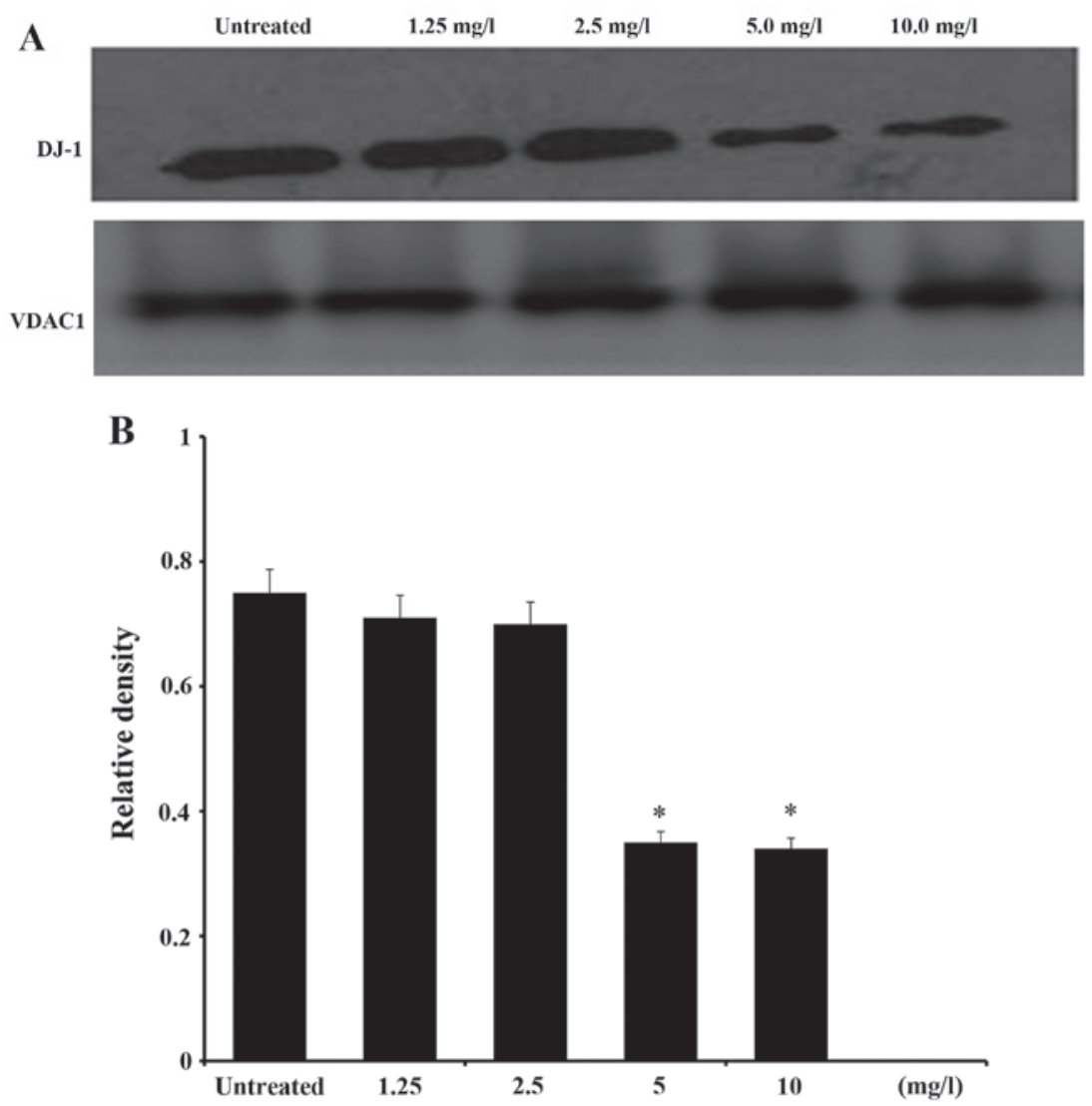

Figure 3. (A) Representative western blot and (B) quantification of band densities of DJ-1 protein expression in the mitochondria of HL-60 cells following treatment with $0,1.25,2.5,5$, and $10 \mathrm{mg} / 1$ DADS for $8 \mathrm{~h}$. VDAC1 was used as a loading control. "P<0.05 vs. untreated controls. DADS, diallyl disulfide; VDAC1, anti-voltage-dependent anion channel 1.

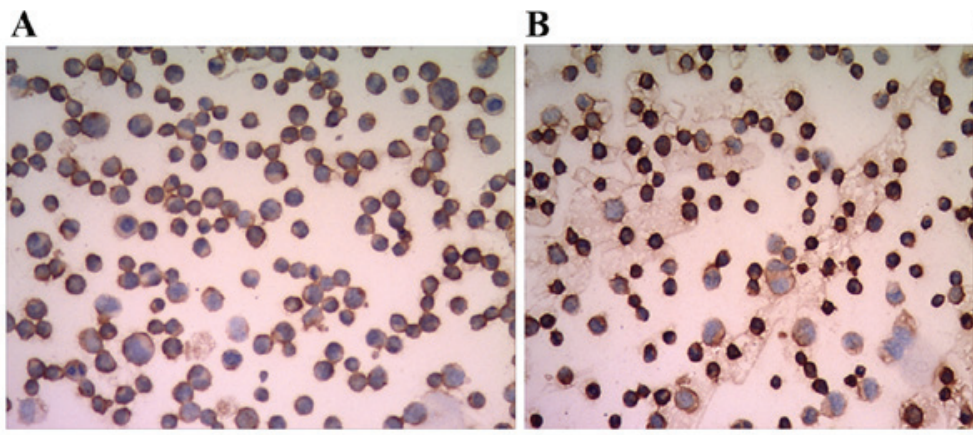

C

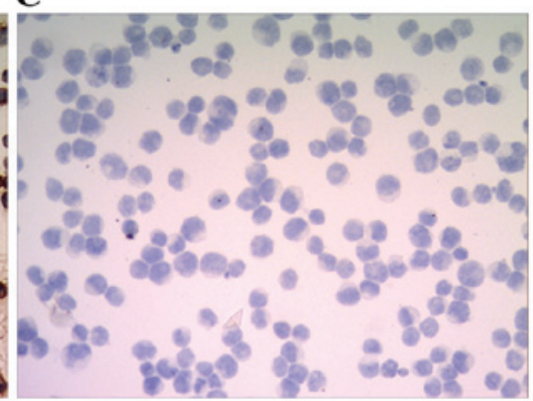

Figure 4. Effect of DADS on the expression and localization of DJ-1 in HL-60 cells as determined by immunocytochemistry. Microscope images (magnification, x40) of DJ-1 expression in HL-60 cells following treatment with $1.25 \mathrm{mg} / 1$ DADS for (A) 0 and (B) $8 \mathrm{~h}$. (C) HL-60 cells that were stained with hematoxylin alone. DADS, diallyl disulfide.

various types of cancer cells $(23,24)$. The results obtained in a previous preliminary study demonstrated that DADS inhibited the proliferation of leukemia cells and induced the differentiation of HL-60 cells following exposure to a low dose $(<1.25 \mathrm{mg} / \mathrm{l})(25)$. At this dose, HL-60 cells were inhibited in $\mathrm{G}_{1}$ phase of the cell cycle; at which point the synthesis of RNA and proteins occurs and DNA synthesis in inhibited, leading to inhibition of cell proliferation and induction of differentiation (25). Treatment of HL-60 cells with a moderate dose of DADS (>1.25 mg/l) has been demonstrated to induce apoptosis of HL-60 cells by inhibiting cell proliferation at the $\mathrm{G}_{2} / \mathrm{M}$ phase, and by inhibiting the ERK and activating the p38 signaling pathways $(12,26)$. The aim of the present study was to investigate the subcellular localization of the DJ-1 protein in HL-60 cells induced by DADS, and provide a basis for further studies into the potential molecular mechanisms underlying the effects of the subcellular localization of the DJ-1 protein in HL-60 cells.

In the current study, HL-60 cells were incubated with $1.25 \mathrm{mg} / \mathrm{l} \mathrm{DADS}$ for $0,4,8$ and $12 \mathrm{~h}$, and the cytoplasmic, nuclear and mitochondrial subcellular fractions of the cells were isolated. Western blot analysis revealed that HL-60 cells treated with $1.25 \mathrm{mg} / \mathrm{l}$ DADS for $8 \mathrm{~h}$ exhibited a significant decrease in DJ-1 protein expression levels in the cytoplasm, and 

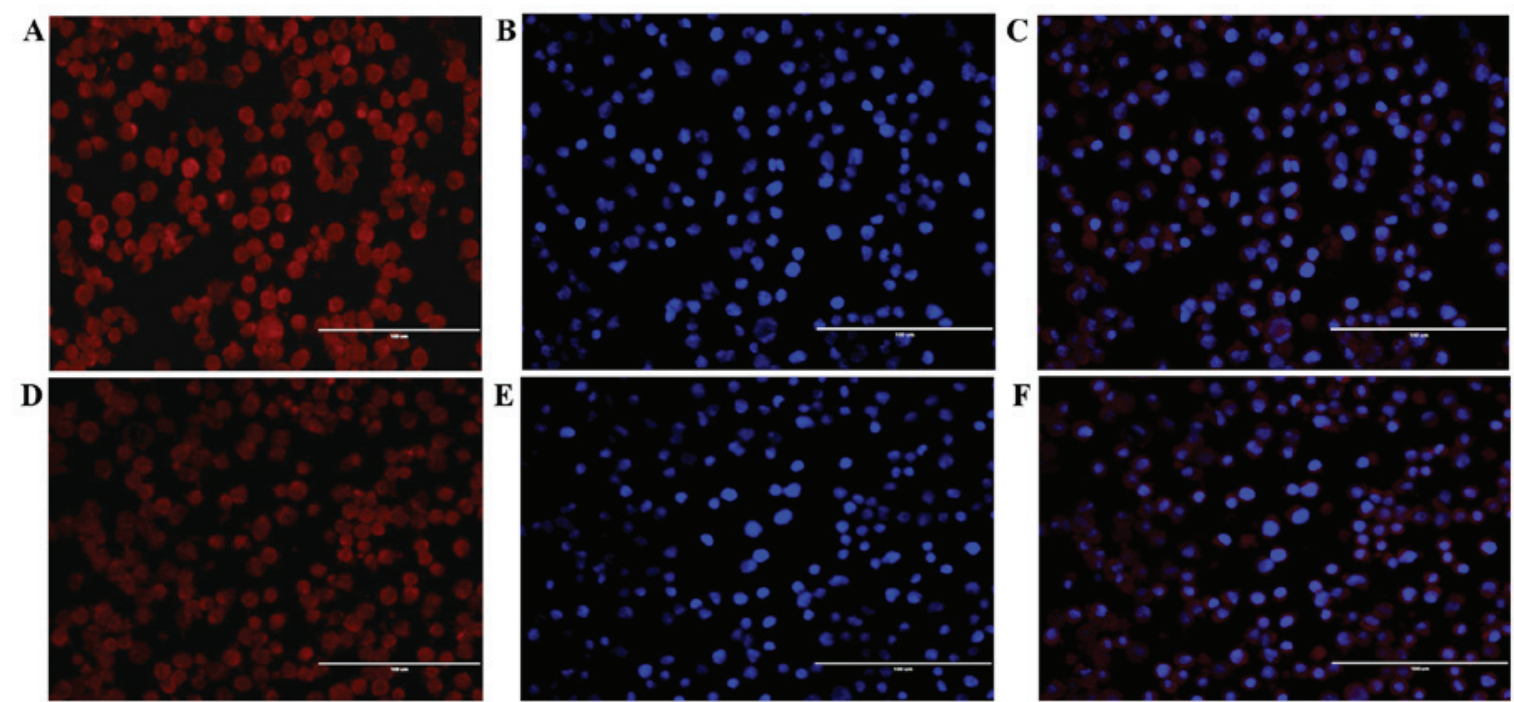

Figure 5. Effect of DADS on the expression of DJ-1 in HL-60 cells as determined using immunofluorescence techniques. Fluorescence microscope images (magnification, x40; scale bars, $100 \mu \mathrm{m}$ ) of (A) DJ-1 expression and (B) the nucleus of untreated HL-60 cells, with (C) DJ-1 and nuclear positioning images merged. Fluorescence microscope images (magnification, x40; scale bars, $100 \mu \mathrm{m}$ ) of (D) DJ-1 expression and (E) the nucleus of HL-60 cells following treatment with $1.25 \mathrm{mg} / \mathrm{l}$ DADS for $8 \mathrm{~h}$, with (F) DJ-1 and nuclear positioning images merged. Nuclear positioning was determined by staining cells with 4',6-diamidino-2-phenylindole.

a significant increase in DJ-1 expression in the nucleus when compared with untreated controls. By contrast, HL-60 cells treated with $1.25 \mathrm{mg} / \mathrm{l}$ DADS for $12 \mathrm{~h}$ exhibited an increase in DJ-1 expression in cytoplasm and decreased expression in the nucleus when compared with cells treated with $1.25 \mathrm{mg} / \mathrm{l}$ DADS for $8 \mathrm{~h}$. These results suggest that DJ-1 protein may be translocated back from the cell nucleus into the cytoplasm following $8 \mathrm{~h}$ of DADS exposure. Immunocytochemistry and immunofluorescence assay analysis results confirmed the observed translocation of DJ-1 from the cytoplasm to the nucleus following exposure to DADS for $8 \mathrm{~h}$. Proteins are often distributed in different subcellular locations, which is associated with their different functions (27). A previous study demonstrated that the DJ-1 protein, which is considered to be involved in the regulation of gene transcription, translocates from the cytoplasm to the nucleus during S phase of the cell cycle upon mitogen stimulation (28). Proteins may regulate gene transcription through DNA acetylation (deactivation), by altering the structure of chromatin or as transcription factors (29). The level of DJ-1 in the nucleus is increased primarily through an increase in the levels of reactive oxygen species (30). DJ-1 modulates gene transcription in combination with specific transcription factors or cofactors, rather than through direct interaction with DNA (31). For example, DJ-1 binds to the DNA-binding region of p53, resulting in repression of the DNA-binding affinity of p53, which decreases Bax expression (32).

Based on the results from previous studies, the observed translocation of DJ-1 from the cytoplasm to the nucleus in HL-60 cells following exposure to a low dose of DADS in the present study, suggests that DJ-1 may function as a binding protein involved in inducing differentiation. It is possible that DJ-1 interacts with additional target proteins and activates the transcription of specific target genes involved in inducing cell differentiation. Nuclear DJ-1 proteins have been demonstrated to inhibit the activity of signal transducer and activator of transcription (STAT) proteins by binding to activated STATs and influencing the transcriptional activity of downstream target genes (33). A previous study demonstrated that a major purpose of nuclear receptor-mediated transfer of proteins into the nucleus is to regulate the transcription of target genes (34). Following regulation, the nuclear receptor may dissociate from DNA and remain in the nucleus or traffic slowly to the cytoplasm (35).

In the majority of tumor cells, DJ-1 is primarily localized to the cell cytoplasm, but is also present in the mitochondria and nucleus $(21,36)$. The specific mechanisms underlying the translocation of DJ-1 require further investigation and confirmation. Low levels of DJ-1 are present in the mitochondria; however, an increase in oxidative stress has been demonstrated to increase mitochondrial DJ-1 expression levels (21). DADS stabilizes the mitochondrial transmembrane potential, and maintains mitochondrial function in response to oxidative stress (25). Mitochondria-target sequence-conjugated DJ-1 has been demonstrated to exert a greater protective role against oxidative stress-induced cell death when compared with nuclear-target sequence-conjugated DJ-1 (28). Mitochondrial dysfunction occurs in DJ-1 knockout mice (37). These findings suggest that mitochondrial DJ-1 serves a role in mitochondrial homeostasis, which is associated with the regulation of cell survival and apoptosis $(38,39)$. In the present study, mitochondrial DJ-1 protein expression levels in HL-60 cells were not significantly altered following treatment with $1.25 \mathrm{mg} / \mathrm{l}$ DADS for 4,8 or $12 \mathrm{~h}$ when compared with the untreated controls. By contrast, mitochondrial DJ-1 protein expression levels were significantly decreased following exposure to 5 and $10 \mathrm{mg} / \mathrm{l}$ DADS when compared with untreated controls. These concentrations of DADS have been previously demonstrated to induce apoptosis in HL-60 cells $(13,14)$. Therefore, these results suggest that expression of DJ-1 in the mitochondria may be associated with induction of apoptosis in HL-60 cells induced by DADS. However, the precise mechanisms involved in mediating this process require further investigation in future studies. 


\section{Acknowledgements}

The present study was supported by grants from the Construct Program of the Key Discipline in Hunan Province of China [grant. no. (2011) 76], the National Natural Science Foundation of China (grant nos. 81100375 and 81400117) and the Platform Open Innovation Fund Project for Hunan Province Universities (grant no. 11K057).

\section{References}

1. Estey E and Döhner H: Acute myeloid leukemia. Lancet 368 : 1894-1907, 2006

2. Jabbour EJ, Estey E and Kantarjian HM: Adult acute myeloid leukemia. Mayo Clin Proc 81: 247-260, 2006.

3. Chen GQ, Zhao Q, Wu YL and Wang LS: Chemical biology study for differentiation and apoptosis of leukemic cell. Shanghai Di-Er Yike Daxue Xuebao 32: 1145-1155, 2012 (In Chinese).

4. Tsiftsoglou AS, Pappas IS and Vizirianakis IS: Mechanisms involved in the induced differentiation of leukemia cells Pharmacol Ther 100: 257-290, 2003.

5. Park HY, Kim ND, Kim GY, Hwang HJ, Kim BW, Kim WJ and Choi YH: Inhibitory effects of diallyl disulfide on the production of inflammatory mediators and cytokines in lipopolysaccharide-activated BV2 microglia. Toxicol Appl Pharmacol 262: 177-184, 2012

6. Su B, Su J, He H, Wu Y, Xia H, Zeng X, Dai W, Ai X, Ling H, Jiang $\mathrm{H}$ and $\mathrm{Su}$ Q: Identification of potential targets for diallyl disulfide in human gastric cancer MGC-803 cells using proteomics approaches. Oncol Rep 33: 2484-2494, 2015.

7. Yi L and Su Q: Molecular mechanisms for the anti-cancer effects of diallyl disulfide. Food Chem Toxicol 57: 362-370, 2013.

8. Luo N, Zhao LC, Shi QQ, Feng ZQ, Chen DL and Li J: Induction of apoptosis in human leukemic cell lines by Diallyl disulfide via modulation of EGFR/ERK/PKM2 signaling pathways. Asian Pac J Cancer Prev 16: 3509-3515, 2015.

9. Zhao J, Huang WG, He J, Tan H, Liao QJ and Su Q: Diallyl disulfide suppresses growth of HL-60 cell through increasing histone acetylation and p21WAF1 expression in vivo and in vitro. Acta Pharmacol Sin 27: 1459-1466, 2006.

10. Yi L, Ji XX, Tan H, Feng MY, Tang Y, Wen L and Su Q Involvement of Mcl1 in diallyl disulfide-induced $\mathrm{G} 2 / \mathrm{M}$ cell cycle arrest in HL-60 cells. Oncol Rep 27: 1911-1917, 2012.

11. Tan H, Su Q, Huang WG, He J and Song Y: DADS-induced apoptosis through the activation of the MAPK pathway in human leukemia cell line HL-60. FEBS J 272 (Suppl 1): S446, 2005.

12. He J, Wan Z, Liao QJ, Tan Z, Zhou XT, Huang WG, Xie HL and $\mathrm{Su} \mathrm{Z}$ : The signal transduction-associated protein in HL-60 cell induced by DADS. Nanhua Daxue Xuebao (Yixueban) 35: 477-480, 2007 (In Chinese).

13. Lee JY, Song J, Kwon K, Jang S, Kim C, Baek K, Kim J and Park C: Human DJ-1 and its homologs are novel glyoxalases. Hum Mol Genet 21: 3215-3225, 2012.

14. Fan J, Ren H, Jia N, Fei E, Zhou T, Jiang P, Wu M and Wang G: DJ-1 decreases Bax expression through repressing p53 transcriptional activity. J Biol Chem 283: 4022-4030, 2008.

15. Clements CM, McNally RS, Conti BJ, Mak TW and Ting JP: DJ-1, a cancer- and Parkinson's disease-associated protein, stabilizes the antioxidant transcriptional master regulator Nrf2. Proc Natl Acad Sci USA 103: 15091-15096, 2006.

16. McCoy MK and Cookson MR: DJ-1 regulation of mitochondrial function and autophagy through oxidative stress. Autophagy 7: 531-532, 2011

17. Fu K, Ren H, Wang Y, Fei E, Wang H and Wang G: DJ-1 inhibits TRAIL-induced apoptosis by blocking pro-caspase- 8 recruitment to FADD. Oncogene 31: 1311-1322, 2012.

18. Tang J, Liu JH, Lan XG, Li ZJ, Liu YW, Zhao MZ, Deng P and Jiang Y: Location and translocation of human DJ-1 protein in eukaryotic cell. Zhongguo Shengwu Huaxue Yu Fenzi Shengwu Xuebao 22: 530-534, 2006 (In Chinese).

19. Junn E, Jang WH, Zhao X, Jeong BS and Mouradian MM Mitochondrial localization of DJ-1 leads to enhanced neuroprotection. J Neurosci Res 87: 123-129, 2009.
20. Vasseur S, Afzal S, Tomasini R, Guillaumond F, Tardivel-Lacombe J, Mak TW and Iovanna JL: Consequences of DJ-1 upregulation following p53 loss and cell transformation. Oncogene 31: 664-670, 2012.

21. Cao J, Lou S, Ying M and Yang B: DJ-1 as a human oncogene and potential therapeutic target. Biochem Pharmacol 93: 241-250, 2015.

22. Wang J, Yang YN, Qin J, Tang YZ, Li QY, Su Z and Tan Z: Diallyl disulfide down regulated DJ-1 inhibiting ability of proliferation and inducing human leukemic cell differentiation. Zhongguo Yaolixue Tongbao 31: 416-420, 2015 (In Chinese).

23. Saud SM, Li W, Gray Z, Matter MS, Colburn NH, Young MR and Kim YS: Diallyl disulfide (DADS), a constituent of garlic, inactivates NF-kB and prevents colitis-induced colorectal cancer by inhibiting GSK-3 3. Cancer Prev Res (Phila) 9: 607-615, 2016.

24. Su B,Su J,Zeng Y,Liu F, XiaH,Ma YH,ZhouZG,Zhang S, Yang BM, Wu YH, et al: Diallyl disulfide suppresses epithelial-mesenchymal transition, invasion and proliferation by downregulation of LIMK1 in gastric cancer. Oncotarget 7: 10498-10512, 2016.

25. Wu MH, Su Z, Cheng AL, Tan Z and Song Y: Experimental study of HL-60 cell differentiation induced by diallyl disulfide. Zhongguo Yaolixue Tongbao 19: 319-322, 2003 (In Chinese).

26. Tan H, Ling H, He J, Yi L, Zhou J, Lin M and Su Q: Inhibition of ERK and activation of p38 are involved in diallyl disulfide induced apoptosis of leukemia HL-60 cells. Arch Pharm Res 31: 786-793, 2008.

27. Poschmann G, Lendzian A, Uszkoreit J, Eisenacher M, Borght AV, Ramaekers FC, Meyer HE and Stühler K: A combination of two electrophoretical approaches for detailed proteome-based characterization of SCLC subtypes. Arch Physiol Biochem 119: 114-125, 2013.

28. Lu L, Sun X, Liu Y, Zhao H, Zhao S and Yang H: DJ-1 upregulates tyrosine hydroxylase gene expression by activating its transcriptional factor Nurrl via the ERK1/2 pathway. Int J Biochem Cell Biol 44: 65-71, 2012

29. Yang X, Li L, Liang J, Shi L, Yang J, Yi X, Zhang D, Han X, Yu N and Shang Y: Histone acetyltransferase 1 promotes homologous recombination in DNA repair by facilitating histone turnover. J Biol Chem 288: 18271-18282, 2013.

30. Josellin AP, Hewitt SJ, Callaghan SM, Kim RH, Chung YH, Mak TW, Shen J, Slack RS and Park DS: ROS-dependent regulation of Parkin and DJ-1 localization during oxidative stress in neurons. Hum Mol Genet 21: 4888-4903, 2012.

31. Kato I, Maita H, Takahashi-Niki K, Saito Y, Noguchi N, Iguchi-Ariga SM and Ariga H: Oxidized DJ-1 inhibits $p 53$ by sequestering p53 from promoters in a DNA-binding affinity-dependent manner. Mol Cell Biol 33: 340-359, 2013.

32. Fan J, Ren H, Jia N, Fei E, Zhou T, Jiang P, Wu M and Wang G: DJ-1 decreases Bax expression through repressing p53 transcriptional activity. J Biol Chem 283: 4022-4030, 2008

33. Oliveira E, Casado M, Raldúa D, Soares A, Barata C and Piña B: Retinoic acid receptors' expression and function during zebrafish early development. J Steroid Biochem Mol Biol 138: 143-151, 2013.

34. Xie JR, Sun F and Liang GY: Effects of xinwei granule on STAT3 and p-STAT3 signal pathway in rats with precancerous lesion of gastric cancer. Zhongguo Zhong Xi Yi Jie $\mathrm{He} \mathrm{Za}$ Zhi 33: 65-70, 2013 (In Chinese).

35. Lin XF and Wu Q: Nucleocytoplasmic shuttling of nuclear receptors and regulatory mechanisms. Xi Bao Sheng Wu Xue Za Zhi Bian Ji Bu 27: 363-368, 2005 (In Chinese).

36. Shinbo Y, Niki T, Taira T, Ooe H, Takahashi-Niki K, Maita C, Seino C, Iguchi-Ariga SM and Ariga H: Proper SUMO-1 conjugation is essential to DJ-1 to exert its full activities. Cell Death Differ 13: 96-108, 2006.

37. Giaime E, Yamaguchi H, Gautier CA, Kitada T and Shen J: Loss of DJ-1 does not affect mitochondrial respiration but increases ROS production and mitochondrial permeability transition pore opening. PLoS One 7: e40501, 2012.

38. Heo JY, Park JH, Kim SJ, Seo KS, Han JS, Lee SH, Kim JM, Park JI, Park SK, Lim K, et al: DJ-1 null dopaminergic neuronal cells exhibit defects in mitochondrial function and structure: Involvement of mitochondrial complex I assembly. PLoS One 7: e32629, 2012

39. Thomas KJ, McCoy MK, Blackinton J, Beilina A, van der Brug M, Sandebring A, Miller D, Maric D, Cedazo-Minguez A and Cookson MR: DJ-1 acts in parallel to the PINK1/parkin pathway to control mitochondrial function and autophagy. Hum Mol Genet 20: 40-50, 2011. 